ing strands being absent or attenuated, there is danger that the partial loss will be confused with a total disappearance. But since at the same time the functions of consciousness are in some measure performed, the fiction of unconscious mental operations arises.

There is a partial recognition of this aspect of the matter in some of the other views of the subject. Thus it is true that certain ' unconscious ideas' are faint psychoses of momentary duration, which hence attract but little attention, including connective attention; it is true, again, that ' ideas' are called 'unconscious' when, perhaps, belonging to the class just mentioned, they fail to be remembered while subconscious or semi-conscious states are obviously such as are not brought into distinct correlation with others, especially with those at the time in the focus of consciousness. The aim of the present discussion, however, is not to dispute the value of these explanations, but to call attention anew to the numerous cases in which the lack of conscious correlation noted constitutes the principal element in the assumed unconsciousness.

If a name be sought for this class of phenomena, psychologists might avail themselves of the classical expression of Leibnitz and say that psychoses of this kind are perceived but not apperceived, that they are perceptions but not apperceptions. And this would be altogether the best designation for them were it not for the wide variation in the meaning of the terms perception and apperception, both in Leibnitz's day and since. In view of this difficulty, in view, also, of the importance of a clear realization of the principle of greater and less complication in consciousness, it has occurred to the writer that, perhaps, we might speak of psychoses or consciousnesses of the first power, second power, third power, or first potence, second potence, third potence, etc. Such phrases would at least have the merit of calling attention to the facts of the case, but their elegance as English and their freedom from misleading associations would raise different questions.

WISLEYAN UNIVERSITY.

A. C. Armstrong, Jr.

\title{
A CASE OF RETARDED PARAMNESIA.
}

So many cases of paramnesia or false memory have been reported and studied that this phenomenon, which was once supposed to be very rare and indicative of insanity, is now regarded as quite common and altogether normal. It may be the same with a peculiarity which 
I have observed in myself for a number of years, but, as $I$ have seen no positive references to it, and as it may throw some light on the mechanism of paramnesia, I am impelled to the disagreeable duty of reporting a personal experience.

In ordinary paramnesia an event which is really happening for the first time in the experience of the subject appears to him to have happened before. The observation of the event is simultaneously accompanied by a vivid flash of memory which represents it as having occurred in all its details at some time in the past. This experience I am familiar with, but it is much more common with me for the false memory to appear not when the event first happens, but at some later time after it happened. For example, I am confronted with a scene which seems and is new to me. It passes from my thoughts, but at some later time when it is recalled to my mind, voluntarily or involuntarily, the impression comes to me suddenly and vividly that I hav looked upon the scene twice in my life under the same circumstances, and I wonder why I did not recognize it when I saw it. Ever afterward the scene remains in my mind as a double memory. The sensation of the paramnesia occurs from a few minutes to several weeks after the real event, but only, if at all, at the first time I think of it. The recollection thus duplicated may be an incident I see or take part in, a view, a picture or a story. The last case in particular, as when sometimes after reading a story in a new magazine I seem to have read it twice, might appear to be susceptible of the usual explanation of paramnesia, that of an imperfect memory of something similar, were it not for the fact that the circumstances of reading the story seem to have been exactly the same in both cases. The longer the time that elapses between the event and its first recollection with the accompanying impression of paramnesia, so much the longer the apparent interval between the events as reported by the false and the true memories, but I am unable to say whether the ratio between the two intervals is really a constant or not. Several instances of retarded paramnesia often occur within a short time, and then months may elapse without such an experience, but I have never been able to connect them with a state of poor health or fatigue.

Diligent inquiry among friends has failed to give any other instances of a similar phenomenon, and the only case $I$ have found in literature is a reference, in Ribot, 'Diseases of Memory' to Pick, Archiv für Psychiatrie, I 876 , but, not having access to the original, I cannot say how far it is similar to mine. Such a case as this, if confirmed by others, will have to be taken into consideration in con- 
structing a theory of paramnesia. It is inconsistent with Lalande's theory, ${ }^{1}$ as well as those of Anjel and Jensen, ${ }^{2}$ unless the memory plays the part of the original perception. The theory of imperfect reminiscence filled out by suggestion is allowable, but does not give a complete explanation.

E. E. Stoosson.

UNIVERSTTY OF WYOMLNG.

\section{MEMORY AND ASSOCIATION.}

I wish to make a correction and comment briefly on Miss Calkins' interesting report of a study of memory and association and comparison with similar experiments made by myself. In no instance did I give the number of words correctly placed in order in each group, but only the numbers placed in the right column or group, as the auditory or the visual; hence her comparisons are not quite correct, and her statement that the Wellesley results do not substantiate the conclusions that "the number of concretes 'recalled' and the number 'recalled in order' would be under ordinary conditions practically the same" is a misquotation and indicates misapprehension. I make no reference to the number ' recalled in order,' or to 'ordinary conditions,' but merely indicate that there was in this experiment practically no false recognition or placing in the wrong column of the concrete objects.

It is interesting to note how nearly the results of the two experiments agree. The better memory of the Wellesley students is probably due to the facts that the external conditions were more favorable and the students more interested in the experiment than the college students tested by myself. It seems to me very probable that the smaller advantage in favor of 'concrete' found by Miss Calkins is due in part to another fact than that mentioned by her, $i$.e., she used pictures of objects while I used real objects. It would be interesting to know just how much difference this would make when all the other conditions are the same. I suspect that the order of increasing effectiveness would be names of objects, mental pictures of objects, real pictures, the objects themselves.

\section{E. A. KirKPATRICK.}

'Lalande: Des Paramnésies, Revue Philosophique, XXXVI., 485. Reviewed by James, Psychological Revirw, I., p. 94 . p. 280 .

2 Krapelin : Arch. f. Psych., 400, in Parish : Hallucinations and Illusions, 